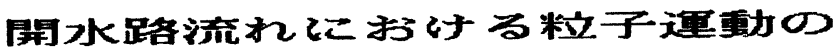 \\ 数值シミュレーション
}

Numerical Simulation of Particle Trajectories in Open Chamel Flow

九州大学工学部 正 員 O大本照薏
九州大学工学部 正 員 平野宗夫
九州大学大学院 学生員 石丸英伸

1.はじめに

浮流砂量の予測には、数学的アプローチの違いにより 拡散方程式を 基礎式とする決定論的手法と 浮流砂の運動を解析しその軌道のアンサンブル集合を取る確率論的手法がある。後者は前者に対し て浮流砂に固有な 運動特性をモデルに取り込むことが比較的容易な点で優れている。しかし、乱流 中の浮遊粒子の挙動が複雑な形態を取り、粒子に作用する外力についても明確ではないために一般的 にその取り扱いはかなり単純化されている。

本研究では、後者の視点より河床上の粒子が 浮上を開始して後再び河床に到達するまでの運動に対 して Basset-Boussinesq-0seen の式に Slip-Shear motion による揚力の 効果を加えた 運動方程式 を基礎式として数值シミコレーションを試みた。その際、流体粒子の運動モデルに一次マルコつ過程を 適用し、浮遊粒子の上昇時および 下降時における抗力、圧力勾配、バセット項、揚力等の各項の寄与 について比較検討を行っている。

\section{2. 浮遊粒子の運動特性}

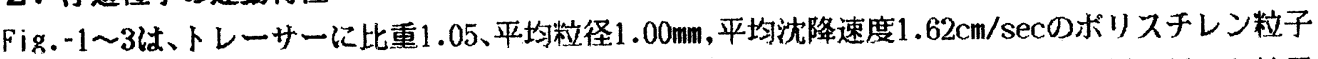
を用いて、水深 $4.80 \mathrm{~cm}$, 摩擦速度 $3.67 \mathrm{~cm} / \mathrm{sec}$ 開水路流れにおける粒子運動の写真解析を行った結果 を示したものである。Fig.-1には、浮遊粒子が河床近傍で間欠的に発生した大規模な組織渦に捕捉さ れて上昇運動を開始し、その後、組織渦から逸脱した粒子は不規則な流体力を受けながら平均的に下 降運動を続ける様子が示されている。又、多くの粒子は河床付近では、河床に接触することなく流れ 方向にほぼ 平行な軌跡を描いている。河床付近では、粒子には、水中重力にバランスする揚力が定 常的に作用していることが示唆される。Fig.-2およびFig.-3 は、粒子の運動特性をさらに詳練にみ るために、各々、粒子の鉛直方向速度および鉛直方向加速度の経時的変化を軌跡上にプロットしたも

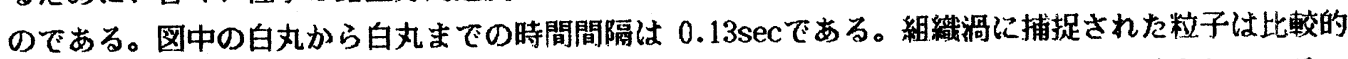
短時間の間に大きな流体力を受けて浮上を開始し、組織渦の発達に伴ってわずかに加速されている。 上昇後、粒子には、不規則な流体力が作用するもののその運動はブラウン粒子のようにランダムでは ない。

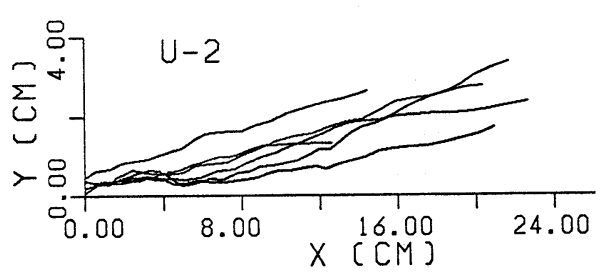

(a) upward process

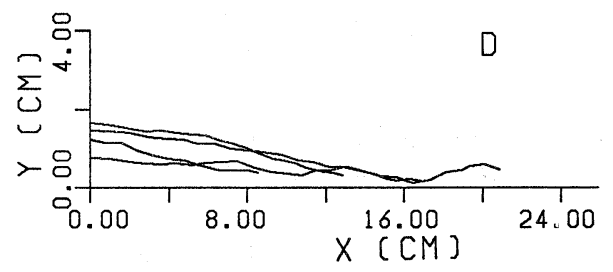

(b) downward process

Fig.1 Obserbed particle trajectories in

(a) upward process and (b) downward process 

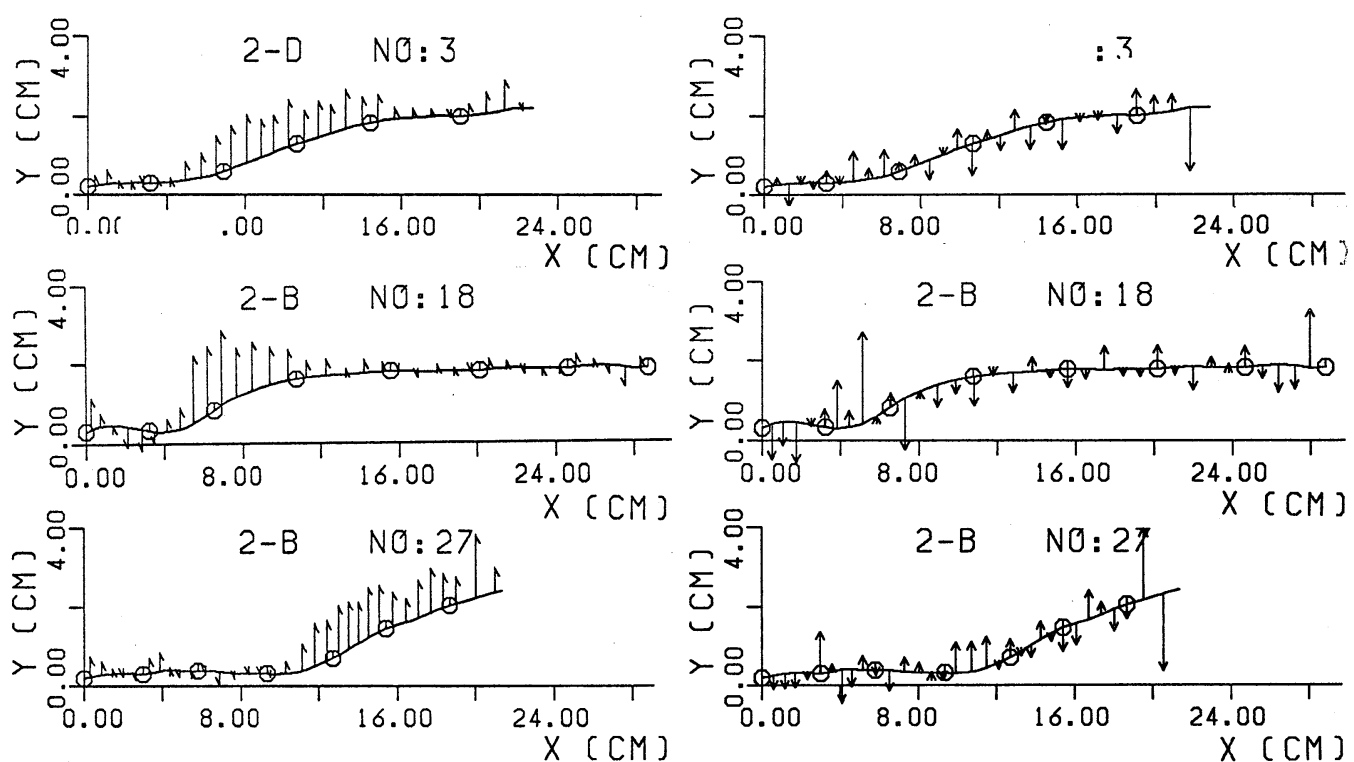

(a) upward process

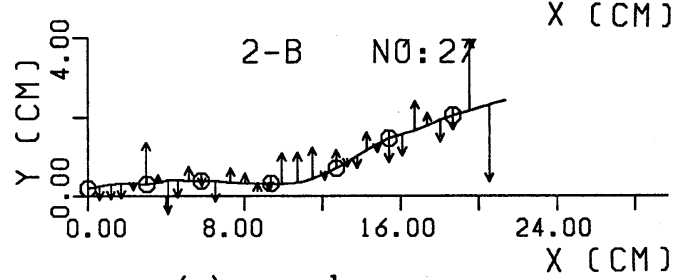

(a) upward process
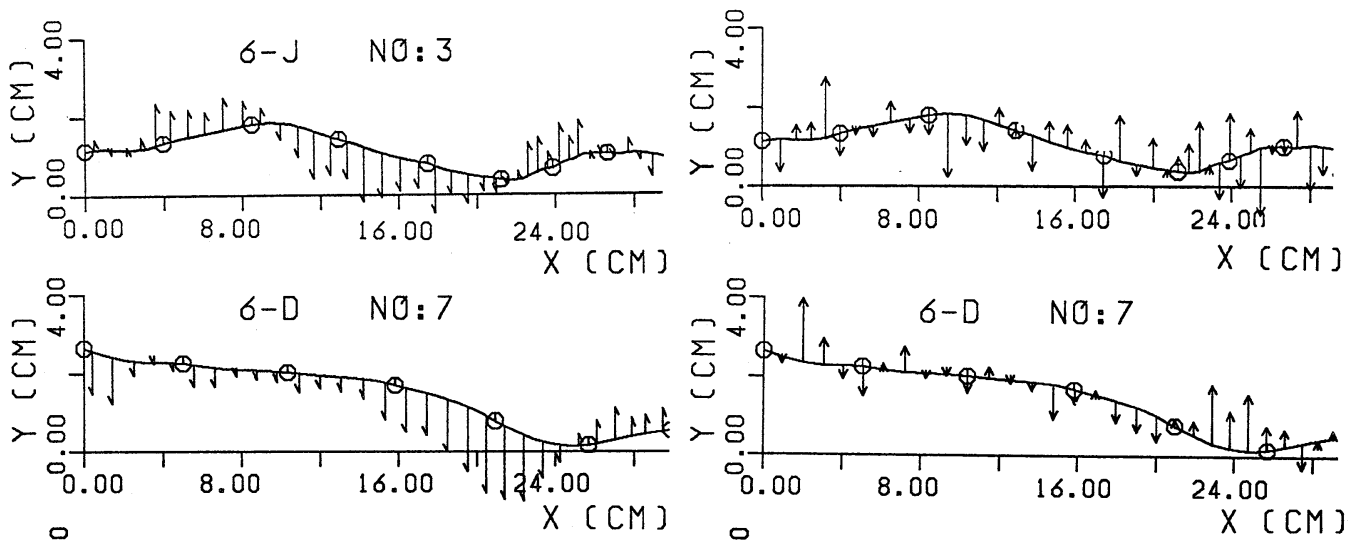

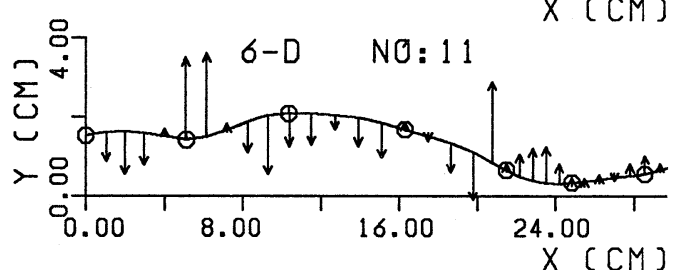

(b) downward process

Fig.2 Variation of vertical velocity along a trajectory of suspended particle $(20 \mathrm{~cm} / \mathrm{s})$

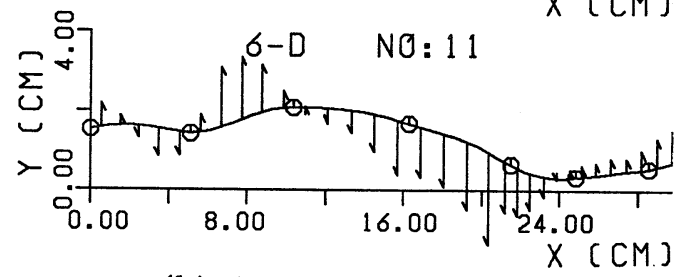

(b) downward process

Fig. 3 Variation of vertical acceleration along a trajectory of suspended particle $\left(200 \mathrm{~cm} / \mathrm{s}^{2}\right)$ 


\section{3. 基磷方程式}

非定常な乱流場における浮遊粒子の運動方程式は、一般にBasset-Boussinesq-0seenの方程式によっ て表される。ところで、二次元せん断乱流場において、浮遊粒子が流体粒子に対して流れ方向に相対速 度を持つ場合粒子には揚力が作用する。Saffmankよれば、壁面は粒子と流れ場の相互作用に対して二 つの働きを持つと指摘されている。一つは、壁面によって粒子に作用する抗力が増加し、流体粒子に 対する粒子の遅れが大きくなる点である。この相対速度は壁面からの距離と粒径に依存するとしてい る。いま一つは、粒子のまわりの流れ場が壁面の存在によって変化を受け、慣性効果が壁面のない場合 と異なってくる点である。Saffmanは第一の効果に着目して 低レイノルズ数において粒子と流体粒子 に相対速度のある場合の揚力を解析的に泳めている。

Basset-Boussinesa-0seen の式にこの揚力の効果を考糜すれば二次元開水路流れにおける流れ方向 および鉛直方向の粒子の運動方程式はおのおの次式によって与えられる。

$$
\begin{aligned}
& \rho_{p} A_{3} d^{3} \frac{d u_{p}}{d t_{p}}=\frac{1}{2} \rho A_{2} d^{2} C_{D} C_{1} V_{r}\left(u_{f L}-u_{p}\right)-A_{3} d^{3} \frac{\partial p}{\partial x}+\frac{1}{2} \rho A_{3} d^{3} \frac{d}{d t_{p}}\left(u_{f L}-u_{p}\right) \\
& +\rho A_{2} d^{2} \sqrt{\frac{36 \nu}{\pi}} \int_{t_{0}}^{t_{p}} \frac{d}{\frac{d \tau}{d \tau}\left(u_{f L}-u_{p}\right)} \frac{\sqrt{t_{p}-\tau}}{d \tau}+F_{p x} \\
& \rho_{p} A_{3} d^{3} \frac{d v_{p}}{d t_{p}}=\frac{1}{2} \rho A_{2} d^{2} C_{D} C_{2} V_{r}\left(v_{f L}-v_{p}\right)-A_{3} d^{3} \frac{\partial p}{\partial y}+\frac{1}{2} \mathrm{PA}_{3} d^{3} \frac{d}{d t_{p}}\left(v_{f L}-v_{p}\right)
\end{aligned}
$$

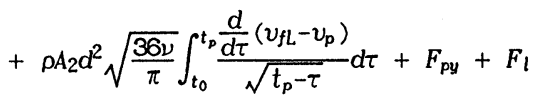

ここに、( $\left.u_{0}, v_{p}\right)$ :粒子の流れ方向および鉛直方向の速度, $\left(\mathrm{u}_{\mathrm{f}}, \mathrm{v}_{\mathrm{f}}\right)$ : 流体粒子の流れ方向 および鉛直方 向の速度， $\rho_{D}, \rho:$ 粒子および流体の密度, $A_{2}, A_{3}$ : 粒子の面積および体積に関する形状係数, $V_{r}:$ 粒 子と流体との相対速度の 絶対值, $F_{\mathrm{D} x}, F_{\mathrm{D} \nu}$ :流れ方向および鉛直方向の外力, $\nu:$ 動粘性係数 $\mathrm{C}_{\mathrm{D}}$ :抗力係数 である。压力勾配は、Navier-Stokesの式により

$$
-\frac{\partial P}{\partial x}=\rho \frac{\partial u_{f}}{\partial t}-F_{x},-\frac{\partial P}{\partial y}=\rho \frac{\partial v_{f}}{\partial t}-F_{y}
$$

によって与えられる。また、 $\frac{d}{d t} ， \frac{d}{d t_{p}}$ はそれぞれ流体および粒子とともに運動する座標から見た 時間微分で次のように近似される。

$$
\frac{d}{d t}=\frac{\partial}{\partial t}+u_{f} \frac{\partial}{\partial x}+v_{f} \frac{\partial}{\partial y}=v_{f} \frac{\partial}{\partial y} \quad, \quad \frac{d}{d t_{p}}=\frac{\partial}{\partial t}+u_{p} \frac{\partial}{\partial x}+v_{p} \frac{\partial}{\partial y}=v_{p} \frac{\partial}{\partial y}
$$

式(1),(2)の左辺は慣性項で、右辺の第一項は抗力、第二項は圧力勾配、第三項は仮想質量を加速す る力、第四項はBasse項、第五項は重力項、(2)式の右辺第六項がせん断流れにおいて 流体と粒子に流れ 方向の相対速度がある場合に働く揚力でSaffmanにより次のように与えられている。

$$
F_{l}=K \mu d^{2}\left(\frac{1}{\nu} \frac{\partial u_{f}}{\partial y}\right)^{\frac{1}{2}}\left(u_{f}-u_{p}\right)
$$

ここに、k=1.615, $\mu$ :粘性係数である。

式(3),(4).(5)を式(1),(2)に代入し、速度スケールに 摩擦速度U*,長さスケールに水深 h, 時間ス ケールにh/U*を用いて無次元化すると浮遊粒子の運動方程式は次のように表される。

$$
\frac{d u_{p}}{d t_{p}}=C_{1} C_{D} \beta \frac{A_{2}}{3 A_{3}} \frac{h}{d} V_{r}\left(u_{f L}-u_{p}\right)+\beta\left(\frac{3 \alpha}{\pi}\right)^{\frac{1}{2}} \int_{t_{0}}^{t_{p}} \frac{d}{\frac{d}{d \tau}\left(u_{f L}-u_{p}\right)} \sqrt{\sqrt{t_{p}-\tau}} d \tau+\frac{1}{3} \beta v_{p} \frac{\partial u_{f L}}{\partial y}+\frac{2\left(\rho_{p}-\rho\right) g h i_{0}}{2 \rho_{p}+\rho} \frac{i_{*}}{u^{2}}
$$




$$
\begin{aligned}
\frac{d v_{p}}{d t_{p}}=C_{2} C_{D} \beta \frac{A_{2}}{3 A_{3}} \frac{h}{d} V_{r}\left(v_{f L}-v_{p}\right)+\beta\left(\frac{3 \alpha}{\pi}\right)^{\frac{1}{2}} \int_{t_{0}}^{t_{p}} \frac{d}{\frac{d}{d \tau}\left(u_{f L}-u_{p}\right)} \frac{1}{\sqrt{t_{p}-\tau}} d \tau+\frac{\partial v_{f L}^{2}}{3 y} \\
-\frac{2\left(\rho_{p}-\rho\right) g h}{2 \rho_{p}+\rho} \frac{g h}{u_{*}^{2}}+\frac{2}{3 A_{3}} K \beta\left(\frac{H}{d}\right) \frac{\left(\frac{\partial u}{\partial y}\right)^{\frac{1}{2}}}{\sqrt{\frac{u_{*} H}{\nu}}}\left(u_{f}-u_{p}\right) \\
\text { ここに、 } \alpha=12 \frac{\left(\frac{h}{d}\right)^{2}}{\left(\frac{u_{h} h}{\nu}\right)}, \beta=\frac{3 \rho}{\left(2 \rho_{p}+\rho\right)}
\end{aligned}
$$

なお、各変数は全て無次元化された形で表示されている。

\section{4. 数值シミュレーション}

粒子の運動経路を、式(5),(6)を基礎式として数值計算するには、入力として粒子が漕遇する流体塊 の Lagrange 的運動特性量を必要とする。しかし、実際には計测上Lagrange的特性量を 求めることは 困蜼であり、その特性について未知な点が多いため、ここではEuler的特吽量を用いる。流速は、時間 平均成分と変動成分の和として表される。平均成分には、対数分布則を適用する。流速変動の運動モ デルに一次マルコフ過程を仮定すれば、ある時刻での流体粒子の変動成分は、1ステップ前の流速変動 が関与する成分とランダム成分との和によって表され次のようになる。

$$
u_{f i}^{\prime}(t+\Delta t)=u_{f i}^{\prime}(t) p \dot{L}(\Delta t)+e_{i}(t+\Delta t)
$$

ここに、 $\rho_{1}(\Delta t)$ は 方向のLagrange的自己相関係数である。 暒れ時間 $\Delta t に$ 対する $\rho_{L}(\Delta t) の$ 関数形は

$$
\rho_{L}(\Delta t)=\exp \left(-\frac{\Delta t}{T_{L}}\right)
$$

のように、指数関数的に減京するものと考える。ここに、T、はLagrange的積分時間スケールであり今本 等によって与えられた開水路流れにおける普遍関数表示が適用されている。粒子の運動を支配する渦 は比較的大きなエネルギーを持ちLagrange的積分スケールの間はその固性を保存するものと考えられ る。ところが、浮遊柆子は、その慣性効果のため、渦と同一の軌跡を描かないことから、ステッブ時 間は、T、に較べて十分に小さく取る必要がある。本研究では、ステップ時間を $\Delta t=0.01 \mathrm{~h} / U *$ と定めた。 また、ランタム成分が二次元正規分布に従うむのと考えれば、 $x$ 方向のランダム成分 $e_{x}$ とy方向のラン ダム成分 $e_{v}$ の生起確率は、前者を事前確率P $\left(e_{x}\right)$ とし、後者を事後確率P $\left(e_{v}\right)$ として、各々、次式で与 えられる。

$$
\begin{aligned}
& P\left(e_{x}\right)=\frac{1}{\sqrt{2 \pi} \sigma_{e x}} \exp \left(-\frac{e_{x}^{2}}{2 \sigma_{e x}^{2}}\right) \\
& P\left(e_{y}\right)=\frac{1}{\sqrt{2 \pi\left(1-r^{2}\right)} \sigma_{e y}} \exp \left\{-\frac{1}{2\left(1-r^{2}\right) \sigma_{e y}^{2}}\left(e_{y}-r \frac{\sigma_{e y}}{\sigma_{e x}} e_{x}\right)^{2}\right\}
\end{aligned}
$$

ここに、 $\sigma_{\theta x}, \sigma_{\theta \nu}$ は各々、 $e_{x}, e_{v}$ の標準偏差である。(7)式の両辺を自剩してアンサンブル平均を取

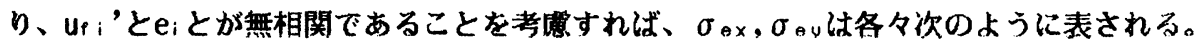

$$
\begin{aligned}
& \sigma_{e x}=\sigma_{x}\left(1-\left\{\rho^{2}(\Delta t)\right\}^{2}\right], \sigma_{x}=\sqrt{u_{L}^{2}} \\
& \sigma_{e y}=\sigma_{y}\left(1-\left\{\rho^{\mu}(\Delta t)\right\}^{2}\right], \sigma_{y}=\sqrt{u^{2}}
\end{aligned}
$$

ここに、 $\sigma_{x}, \sigma_{y}$ は各々、流れ方向および鉛直方向の Euler的流速変動の標準偏差である。ランダム 成分は、時系列的には独立であるが 空間的には 相関を持ち、 $e_{x}, e_{y}$ の相関係数 $\curlyvee$ ば次式で与えられる。

$$
\gamma=-\left(1 \frac{y}{h}\right)\left(\frac{u_{*}^{2}}{\sigma_{x} \sigma_{y}}\right)
$$


次ぎに、压力項およびバセット項については以下ののように取り扱われている。粒子の運動特性の ところでも触れたように、河床付近では粒子の重力効果を減殺する上向きの揚力が定常的に作用して いることが読み取られた。鉛直方向の平均圧力勾配は Reynolds の運動方程式からも明らかなように、 鉛直方向の乱れの強さの深さ方向に関する公配と関係している。壁面乱流において計測された中川・

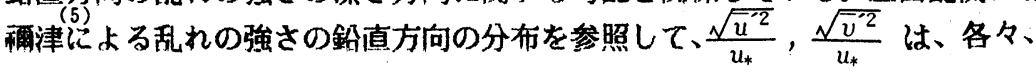

$$
\frac{\sqrt{u^{2}}}{u_{*}}=\left\{\begin{array}{ll}
2.30 \exp \left(-\frac{y}{h}\right) & (0.1 \leqq y / h \leqq 1.0) \\
2.08\left(\frac{10 \cdot y}{h}\right)^{\frac{1}{2}} & (0 \leqq y / h \leqq 0.1)
\end{array}, \frac{\sqrt{v^{\prime 2}}}{u_{*}}=\left\{\begin{array}{l}
1.27 \exp \left(-\frac{y}{h}\right)(0.1 \leqq y / h \leqq 1.0) \\
1.15\left(\frac{10 \cdot y}{h}\right)^{\frac{1}{2}}(0 \leqq y / h \leqq 0.1)
\end{array}\right.\right.
$$

で与えられている。また、流体と粒子との相対加速度の履歴を表すバセット項は、各ステップにおい て平均傎の定理を適用すれば、

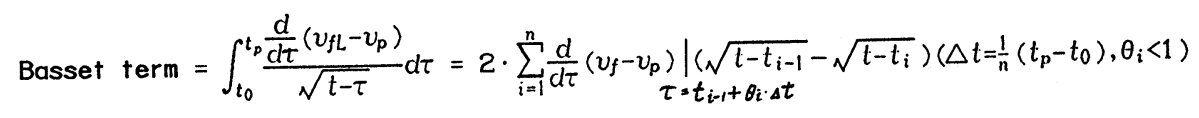

によって表される。

浮遊粒子の軌跡は、式(6),(7)を基礎式として、Runge-Kutta法 を用いて数值計算されている。その 際、各ステップにおける流速変動 Uf', $V_{f}{ }^{\prime}$ は、式(10),(11)に基つ”いて模擬乱数を発生させ、式(8)に より与えられる。

\section{5. 計算結果とその考察}

数值シミュレーションは、粒子を半水深の位置より 出発させ河床に到達するまでの運動と、河床か ら浮上を開始し再び着床するまでの運動の二種類を対象として行われた。

Fig.-4は、半水深から粒子を投入した場合の平均飛距離について実測值と計算值を比較したものであ る。綎軸には平均飛距離を投入高さ将で無次元化され、横軸は局所平均流速について河床から投入高 さまで鉛直方向に積分して求められた平均流速 を静水中の沈降速度Wのて無次元化されている。図中 の破線は、粒子が静水中の沈降速度で流下した場合の飛距離である。計算值は 実測值と概ね良く一致 しており、本シミュレーション法の妥当であることが検証された。なお、相対水深が0.1以下では揚圧 力は重力項の約 $10 \%$ であった。半水深からの粒子の運動に対しては、バセット項を入れた場合とそう で無い場合で飛距離に大きな差異は認められなかった。

次ぎ、粒子が河床近傍から浮上し再び着床するまでの一連の過程に 対する数值シミュレーション においては、粒子の浮上過程における組織渦の奇与は未だに 不明な点が多い。ここでは、Fig.-3に見 られるように比較的短時間に粒子が加速されることおよびGrassの水素気泡による流れの可視化実験の 結果を参考にして、粒子が捕捉される組織渦は局所平均流速の70\%の移流速度で、河床に対して $30^{\circ}$ の向 きに上昇運動を開始し、その影響は指数関数的に減衰するものと考える。

各ステップにおいて外力項を抽出した結果、粒子の浮上に支配的な外力としては、抗力と同時に せ ん断流れにおいて流体と粒子に流れ方向の相対速度がある場合に生じる揚力も 無視できないこと、さ らに流体運動において自己相関係数をぜロとして計算した場合、各ステップにおける鉛直方向の速度の 変化が 急激で実測値を説明できないこと等が認められた。FIG.-5,6は、各々、平均飛距離と平均飛高 の計算傎を実測值と比較したものである。実測データのサンプル数虫平均約 50個で少ないために計算 値と実測值に関して十分な比較はできないが、計算值は今回得られた実澒值の傾向をほほ表している こと放かる。 


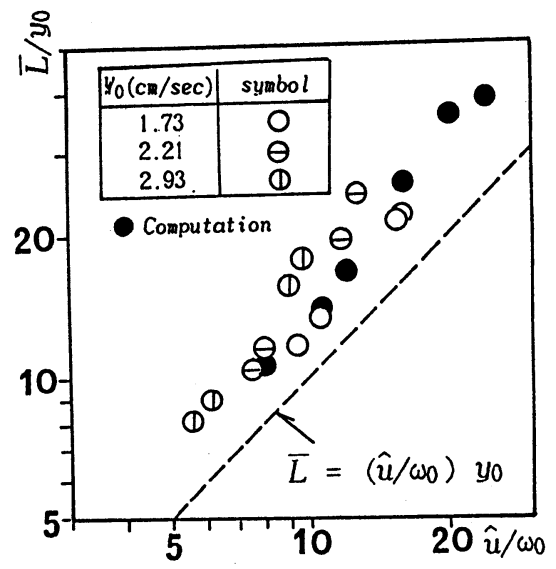

Fig.4 Comparison of computed results and measured ones

6. あとがき

本研究では、Basset-Boussineq-0seen の式に Slip-shear motionによる揚力の効果を取り入れ た浮遊粒子の運動方程式を基礎式とし、流体粒子 の運動モデルに一次マルコフ過程を適用した粒 子腪動の数犆シミュレーション法を提示した。次 ぎに、半水深から投入された粒子の軌跡について 実㵋值と 計算值を比較した結果、本シミュレー ション法 の妥当であることが検証された。また、 河床から浮上し 再び着床するまでの粒子の運動 に対しては、Slip-shear motionによる揚力の効 果が無視できないことおよび 乱れの強さの鉊直 方向の分布による揚压力は河床付近では 重力項 の約10\%程度であることが認められた。

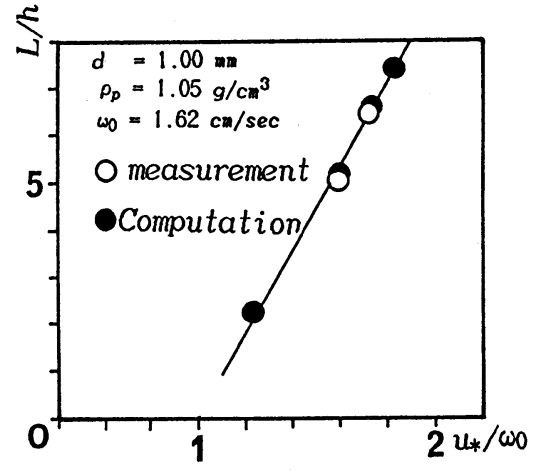

Fig. 5 Relationship between flying length and the ratio of shear velocity to settling one

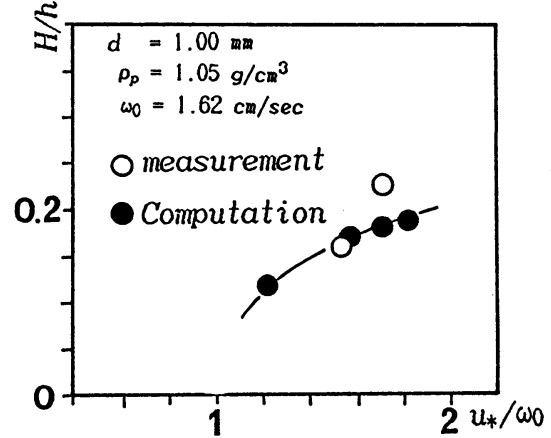

Fig.6 Relationship between flying height and the ratio of shear velocity to settling one

\section{参考文献}

1)声田・藤田・向井：粒子の浮遊運動のモデルと浮遊砂量, 第29回水理講演会論文集, 1985

2)Saffman, P.G.: The lift on a small sphere in a slow shear flow, I.F.M.vol.22, part2,1965

3)Grass,A.J.: Structural features of turbulent flow over smooth and rough boundaries. I.F.M. 50,1971

4)今本, 浅野, 石垣・今西：開水路流れにおける乱れ特性量の普遍関数表示について(2), 京大防災研 年報第20号B 1977

5) Nakagawa,H.\& Nezu, I: Prediction of the contributions to the Reynolds stress from the bursting events in open channel flows, I.F.M.vol.80,1977 